\title{
PROSPECTING OF PHENYLPROPANOIDS AND
}

TERPENOIDS IN EAST INDIAN SANDALWOOD

(SANTALUM ALBUM L.) 


\title{
PROSPECTING OF PHENYLPROPANOIDS AND TERPENOIDS IN EAST INDIAN SANDALWOOD (SANTALUM ALBUM L.)
}

\author{
Thesis submitted to \\ Indian Institute of Technology, Kharagpur \\ for the award of the degree \\ of \\ Doctor of Philosophy \\ by
}

Biswapriya Biswavas Misra

under the guidance of

Prof. Satyahari Dey

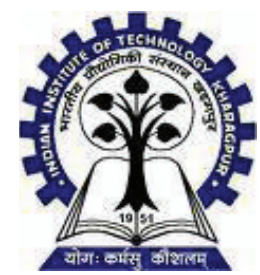

DEPARTMENT OF BIOTECHNOLOGY

INDIAN INSTITUTE OF TECHNOLOGY, KHARAGPUR

JANUARY 2010

(C) 2010, Biswapriya Biswavas Misra. All rights reserved. 


\section{CERTIFICATE OF APPROVAL}

Certified that the thesis entitled PROSPECTING OF PHENYLPROPANOIDS AND TERPENOIDS IN EAST INDIAN SANDALWOOD (SANTALUM ALBUM L.) submitted by BISWAPRIYA BISWAVAS MISRA to Indian Institute of Technology, Kharagpur, for the award of the degree of Doctor of Philosophy has been accepted by the external examiners and that the student has successfully defended the thesis in the viva-voce examination held today.

$\begin{array}{lll}\begin{array}{l}\text { Dr. Amit K. Das } \\ \text { (Member of the DSC) }\end{array} & \begin{array}{l}\text { Dr. Sudip K. Ghosh } \\ \text { (Member of the DSC) }\end{array} & \begin{array}{l}\text { Dr. Adinpunya Mitra } \\ \text { (Member of the DSC) }\end{array}\end{array}$

Dr. Satyahari Dey

Dr. Amit K. Das

(Supervisor)

(External Examiner)

(Chairman) 


\section{Department of Biotechnology}

\section{Dr. Satyahari Dey}

\section{Professor}

\section{CERTIFICATE}

This is to certify that the thesis entitled Prospecting of phenylpropanoids and terpenoids in East Indian Sandalwood (Santalum album L.), submitted by Biswapriya Biswavas Misra to Ind ian Institute of Technology, Kharagpur, is a record of bonafide research work under my supervision and is worthy of consideration for the award of the degree of Doctor of Philosophy of the Institute.

Supervisor

Prof. Satyahari Dey

Date: 


\section{DECLARATION}

I certify that

a. the work contained in this thesis is original and has been done by me under the guidance of my supervisor.

b. the work has not been submitted to any other Institute for any degree or diploma.

c. I have followed the guidelines provided by the Institute in preparing the thesis.

d. I have conformed to the norms and guidelines given in the Ethical Code of Conduct of the Institute.

e. whenever I have used materials (data, theoretical analysis, figures, and text) from other sources, I have given due credit to them by citing them in the text of the thesis and giving their details in the references. Further, I have taken permission from the copyright owners of the sources, whenever necessary.

Biswapriya Biswavas Misra 


\section{PREFACE}

The East Indian Sandalwood (Santalum album L.) is a highly valuable and precious woody tropical tree, much admired for its fragrant heartwood, scented oil for its aesthetic uses and pharmacological applications.

Pioneering efforts of Indian Institute of Science (IISc), Bangalore and Bhabha Atomic Research Centre, Mumbai allowed early inroads into sandalwood tree biotechnology through several phases, i.e., (1) development of biotechnological means of micropropagation through tissue cultural practices, (2) improvisation in conventional silvicultural methods and timber quality improvement, (3) revelation of underlying biochemical processes associated with growth and development and (4) work on accumulation patterns, quantitative studies and chemical properties of sandalwood oil. The laboratory of Prof. Satyahari Dey, at Indian Institute of Technology Kharagpur had significant contributions since, 1990; in large scale production of in vitro tissues through bioreactors as a means for rapid mass propagation and commercialization through institute and industry collaborative Technology Development Mission (TDM) project sponsored by Govt. of India and the Tata Tea Ltd. The next phase of sandalwood research in this laboratory went one step ahead through the 'Bioprospecting of Novel Genes and Molecules from Sandalwood' in the form of a substantial grant from Department of Biotechnology (DBT), Ministry of Science and Technology, Govt. of India.

This thesis is based upon studies conducted during September, 2004 to December, 2009 at the Plant Biotechnology Laboratory, Department of Biotechnology, IIT Kharagpur under the supervision of Prof. Dey and written to address the potential of this lesser explored tropical forest tree, as a rich source of phytaceuticals and genetic information to provide future guidance towards the development of value-added products, thus 'bioprospecting'. The framework within which this research was supported has certainly left its mark on large parts of this thesis, where the focus was to uncover the underlying metabolite pools and diversities using modern technological solutions, and addressing the intricacies of the biochemistry, metabolite pools, proteins and genes by implementation and thorough evaluation of both newly adopted and existing techniques for this work. It provides fairly new information that has many facets that remain to be explored both, by people in academia, related to terpenoid biology, forest biotechnology and pharmacology, as well as people in industry involved with development of alternative medicine and pharmaceuticals. Though the sandalwood fragrance related research have been dominating the scientific literature in the past, this work would take it a step further to reveal the potential of in vitro grown tissues as alternative sources for production of sandalwood oil fragrance constituents. Chemosynthesis of sandal-fragrancemimic molecules, increased adulteration of commercially available oil and upsurge in marketability of taxonomically and chemically unrelated plant essential oils as 'sandalwood 
oil' put a serious question mark towards identification and authentication of true oils. In vitro biology of sandalwood is extended a step forward to pave way to uncover the hidden commercialization potentials through this work. This thesis will seek to help familiarize people with the bioactive molecules involved in regards to its ethnopharmacological properties and shed light on some of the genetic basis that produces such fragrance. The work included as Appendix is found in the attached $\mathrm{CD}$ with the thesis as well as at the personal webpage of author, http://sites.google.com/site/bbmisranow/.

This investigation covered basic biochemistry addressing some questions unique to this typical plant, to sometimes reaching the state-of-the-art hyphenated techniques to gather the complicated information embedded within the metabolome, instrumentation to fingerprint the developmental stages while at times unraveled the genetic machinery involved and finally explored the biologically active molecules to get insights into their potential activity for use as commercial therapeutic plant- products.

Within the available time frame and instrumental resources, this first time attempt on metabolite profiling/ bioprospecting resulted in new information on metabolites biosynthesized in cultured cells and tissues in sandalwood. The author realized that further exploration will reveal huge scope of producing in vitro, the aromatherapeutic phytomedicinals. It would have been the author's satisfaction had the biological activities been conducted with isolated compounds. But he is hopeful that his laboratory will soon achieve this success of scaling up, so that individual compounds will be available for this exercise. The thesis reports the first ever detection of santalols from cultured cells and tissues and the IPR protection is ensured. 


\section{ACKNOWLEDGEMENT}

This doctoral thesis would not have been possible without close interaction, inspiration and advice from numerous individuals, where acknowledging each individual would be an uphill task.

First and foremost, I would like to express my deepest sense of gratitude and indebtedness to my guide, philosopher, advisor and local guardian Prof. Satyahari Dey, for his constant involvement, motivation, insights and guidance, his tenacity to bear all my troubles, sharing the pain and happiness of my academic and professional life throughout my research work. His optimistic personality, persuasion towards application and commercialization aspects of basic research improved my fervor to carry out research in plant biotechnology.

I express my gratefulness to Head of the Department, Prof. A K. Das for his help through facilitation of the presentations, seminars and organizing the DSC meetings. Not to forget his protein engineering and bioseparation lectures.

I express my gratitude to the ex-Head of the Department, Prof. A. K. Ghosh allowing scholarships and leaves apart from experimental designing in sandalwood molecular biology and his unforgettable recombinant DNA and gene expression classes. I am extremely indebted to Prof. T. K. Maiti for his advice in immunology related work in sandalwood as well as for taking care of my academic and administrative records all through these five years. I am highly grateful to Prof. Subhas C. Kundu for his moral support, interactions and heavy doses in lighter veins as well as allowing to use his laboratory facilities. I also express my gratitude to Prof. Debabrata Das for his advices and inspirational chats. I express my gratitude to Prof. S. K. Ghosh for his timely guidance and suggestions in molecular biology work. I would also extend my thankfulness to Prof. Mrinal K. Maiti for his encouragements, Dr. R. K. Sen for his inspirations, Dr. A. S. Ghosh for his cheerful greetings in return whenever I wished and lectures on 'domain swapping', Dr. R.P. Bahadur for his invaluable suggestions in bioinformatics work and lastly Dr. P. Sar. Special gratitude for Prof. Adinpunya Mitra, AGFE for making his laboratory facilities and some reagents available to me.

I am highly grateful to Prof. Wilhelm Gruissem for providing me an opportunity to work in the Isoprenoid Group, Plant Biotechnology, at ETH, Zurich through Indo Swiss Bilateral student exchange programme for four and half a months, alongside my immediate boss Dr. Eva Vranova , Postdoc, for my training in Arabidopsis for metabolic pathway studies and mutant analysis. My deepest gratitude to PD Dr. Christoff Sauter for his help in confocal and fluorescence microscopy at ETH. I am also grateful to Prof. D. Mal and Prof. Sujit Roy, Department of Chemistry for analytical chemistry suggestions, Prof. Nirupama Mallick for motivation. I extend my deepest sense of gratitude for Prof. Pradeep K. Chand, P. G. 
Department of Botany, Utkal University for motivating me towards research and inspired me to qualify CSIR-NET and a person whom I always admire and idolize in R and D.

I am grateful to Dr. Sanjay Pal for inducting me into sandalwood research, Dr. Nandita Mishra, the energetic laboratory senior Dr. Prajjal K. Singha, immediate senior Dr. Suryakumar, Dr. Sonal Roy. I would heartily thank Dr. Ratna Chaturvedi for her valuable painstaking corrections, suggestions and valuable corrections by my juniors, Mr. Shibendu S. Das and Ms. Mousumi Biswas, also Abheepsa for her corrections, Dibyendu to carry forward my work in sandalwood and laboratory helps from Mr. Kamal Kar and Swapan Giri. Special mention for Mr. Prokash Saha for teaching me plant tissue culture, bioreactors; Dr. Shanti Mondal for HPLC, MALDI-ToF analysis at Institute CRF, Mr. Samiran for sole help in LCMS/ MS and MALDI-ToF analyses. Dr. Ramapati Samanta for facilities at departmental CRF and Mr. Debasish Gayan in GC, HPLC and confocal analysis. Among departmental seniors I would like to acknowledge my research scholar idol and inspiration Dr. Rupesh Dash, ever helping Dr. Sobhan Roy, ever inspiring Mr. Suvankar Ghorai, Mr. Mrinmoy Chakaraborty, Dr. Chitrangada Acharaya, Dr. Dipanjan Ghosh, Dr. Mahendran, Dr. Murthy, Dr. Chaitanya, Mr. Tamal Das, Dr. Biman B. Mandal, Dr. Meher who always had a piece of advice for my academics, as well as for their constant guidance and help in work. I profusely thank all the office staffs; Sandeepda, Sukhdevda, Govindada, Bhagirathida, Paritoshda, Madam, Bholada, Rintuda, Joy, Nimai, Santosh and Pradeep. Special mention for Dr. Debabrata Sircar and Dr. Ranjan Nanda, AGFE, Dr. Bikash Jena, Chemistry for their enlightening discussions. I thank all the B. Tech. (Mr. Rahul Nahar, Suvendu, Kabeer, Arupananda, Erina, Sonic, Satyakam, Sourav, Gyan, Sheetal), M. Tech. (Puneet, Manoj, Girish, Santosh, Arun, Praveen) and trainees (Mr. Sudarshan Mukherjee, Sucharita) who have worked alongside me. Among juniors, I would like to extend my gratefulness to all of them. Special mention for my best friend of the campus and may be the whole life, Mr. Suneel Gupta, AGFE for his tremendous mental support, academic and financial help and inspiration through out my career. I will be always indebt to him life long. My best friends; Ravi, Jyoti, Sulin, Prasanna, for their constant encouragement. Above all, the inspiration, support, monetary help provided by my father (Mr. Hari Har Misra) and my mother (Mrs. Indumati Misra) cannot be expressed in words and Goddess Saraswati and Lord Jagganath and Lokanath.

Lastly, I am thankful to CSIR, India for all the financial support to me as JRF and SRFships, ISBRI for financial support to visit ETH, Zurich. I also thank all the staff members of Academic section and Sponsored research and Industrial Consultancy (SRIC), for the administrative support and those of the Central Library for academic help, technical help from CWISS and CRF of our institute, HMC for my accommodation.

IIT Kharagpur

January, 2010

(Biswapriya Biswavas Misra) 


\section{LIST OF ABBREVIATIONS}

2, 4-D

2, 5-DHB

2D

3D

Aa

ABTS

ACT

AD

ALP

ANOVA

AOAC

APase

ATCC

ATP

BA

BHT

BLAST

Bp

BSA

BW

CA

CA

CAD

CAS

CAT

CDD

cDNA

$\mathrm{CFU}$

ChE

CLSM

CNS

CoA

CTAB

CV

CVD

D2

$\mathrm{Da}$

$\mathrm{DAB}$

DABC

DAD

DAPI

$\mathrm{ddH}_{2} \mathrm{O}$

DMAPP

DMEM
2, 4-Dichlorophenoxyacetic Acid

2, 5-DiHydroxy Benzoic acid

Two Dimensional

Three Dimensional

Amino Acid

2, 2' Azino Bis (3-ethylbenzo) Thiazoline-6-Sulfonic acid

Actin

Alzheimer's Disease

Alkaline Phosphatase

Analysis Of Variance

Association of Official Analytical Chemists

Acid Phosphatase

American Type Culture Collection

Adenosine TriPhosphate

6-BenzylAminopurine

Butylated Hydroxyl Toluene

Basic Local Alignment Search Tool

Base pair

Bovine Serum Albumin

Body Weight

Callus

Cluster Analysis

Coniferyl Alcohol Dehydrogenase

Chemical Abstracts Service

Catalase

Conserved Domain Database

Complementary DeoxyriboNucleic Acid

Colony Forming Unit

Cholinesterase

Confocal Laser Scanning Microscopy

Central Nervous System

Coenzyme A

Cetyl Trimethyl Ammonium Bromide

Color Value

CardioVascular Disease

Deuterium

Dalton (= $1 \mathrm{amu})$

3, 3-DiAminoBenzidine tetra hydrochloride

Drug Administration Bureau of China

Diode Array Detector

4', 6-DiAmidino-2-PhenylIndole

double distilled water

DiMethyl Allyl Pyrophosphate

Dulbecco's Modified Eagle Medium 


\begin{tabular}{|c|c|}
\hline DMSO & Dimethyl SulfOxide \\
\hline DNA & DeoxyriboNucleic Acid \\
\hline dNTP & DeoxyNucleotide TriPhosphate \\
\hline DPPH & 1, 1-DiPhenyl-2-PicrylHydrazyl \\
\hline DTNB & 5', 5-DiThio-bis- (2-NitroBenzoate) \\
\hline DTT & DiThioThreitol \\
\hline DW & Dry Weight \\
\hline DXP & 1-Deoxy-D-Xylulose 5-Phosphate \\
\hline DXS & 1-Deoxy-D-Xylulose 5-Phosphate Synthase \\
\hline E. coli & Escherichia coli \\
\hline EA & Enzyme Activity \\
\hline EAS & Epi-Aristolochene Synthase \\
\hline EB & Elution Buffer \\
\hline EBV & Epstein-Barr Virus \\
\hline $\mathrm{EC}$ & Enzyme Commission \\
\hline Ecm & Extracellular Matrix \\
\hline EDC & 1-Ethyl-3-(3-Dimethylaminopropyl) Carbodiimide \\
\hline EDTA & Ethylenediaminetetracetic Acid \\
\hline ELISA & Enzyme Linked Immuno Assay \\
\hline EMEA & European Medicines Agency \\
\hline ESI-MS & Electron Spray Ionization-Mass Spectroscopy \\
\hline $\mathrm{EST}$ & Expressed Sequence Tags \\
\hline $\mathrm{EtOH}$ & Ethyl Alcohol \\
\hline$E$-value & Expected value \\
\hline FARM & First Aspartate-Rich Motif \\
\hline FBS & Fetal Calf Serum \\
\hline FCR & Folin Ciocalteau's Reagent \\
\hline FDA & Food and Drug Administration \\
\hline FEMA & Flavor and Extract Manufacturers Association \\
\hline FITC & Fluorescein IsoThioCyanate \\
\hline FPP & Farnesyl Pyrophosphate (Diphosphate) \\
\hline FPPS & Farnesyl Pyrophosphate Synthase \\
\hline FRAP & Ferric Reducing Assay Power/ Ferric Reducing Ability of Plasma \\
\hline FTIR & Fourier Transform Infra Red Spectroscopy \\
\hline FW & Fresh Weight \\
\hline GA3 & Gibberellic Acid \\
\hline GAP & GlycerAldehyde-3-Phosphate \\
\hline GC & Gas Chromatography \\
\hline GC-FID & Gas Chromatography-Flame Ionization Detection \\
\hline GC-MS & Gas Chromatography-Mass Spectrometry \\
\hline GelDoc & Gel Documentation \\
\hline GFC & Gel Filtration Chromatography \\
\hline GGPP & Geranyl Geranyl Pyrophosphate \\
\hline GLC & Gas Liquid Chromatography \\
\hline GPP & Geranyl Pyrophosphate \\
\hline HBSS & Hanks Balanced Salt Solution \\
\hline HEPES & 4-(2-HydroxyEthyl)-1-PiperazineEthaneSulfonic acid \\
\hline
\end{tabular}




\begin{tabular}{|c|c|}
\hline HMGCoAR & 3-Hydroxy-3-Methyl-Glutaryl-CoA Reductase \\
\hline HPLC & High Pressure Liquid Chromatography \\
\hline HPTLC & High Performance Thin Layer Chromatography \\
\hline HPV & Human Papilloma Virus \\
\hline HRP & Horse Radish Peroxidase \\
\hline HSV & Herpes Simplex Viruses \\
\hline HW & Heartwood \\
\hline IAA & Indole-3-Acetic Acid \\
\hline IBA & Indole-3-Butyric Acid \\
\hline $\mathrm{IC}_{50}$ & $50 \%$ Inhibition Concentration \\
\hline $\mathrm{IgG}$ & Immunoglobulin $\mathrm{G}$ \\
\hline IPP & Isopentyl Pyrophosphate \\
\hline $\mathrm{Kbp}$ & Kilo basepair \\
\hline $\mathrm{kDa}$ & kiloDalton \\
\hline $\mathrm{KI}$ & Kovat's Index \\
\hline LB & Luria-Bertani \\
\hline LC-MS & Liquid Chromatography-Mass Spectroscopy \\
\hline $\mathrm{LD}_{50}$ & $50 \%$ Lethal Dose \\
\hline LRI & Linear Retention Index \\
\hline $\mathrm{m} / \mathrm{z}$ & mass to charge ratio \\
\hline MALDI-ToF & Matrix-Assisted Laser Desorption Ionization-Time of Flight \\
\hline MDA & MalonDiAldehyde \\
\hline MEP & 2-C-Methyl-Erythritol 4-Phosphate \\
\hline MES & 2-(N-Morpholino) EthaneSulfonic acid \\
\hline MGYP & Malt extract-Glucose-Yeast extract-Peptone \\
\hline MHB & Mueller Hilton Broth \\
\hline MIC & Minimal Inhibitory Concentration \\
\hline $\mathrm{mM}$ & milli Molar \\
\hline MMP & Matrix Metallo-Proteinase \\
\hline MOPSO & 3-(N-MOrPholino)- 2-hydroxypropaneSulfOnic acid \\
\hline mRNA & messenger RiboNucleic Acid \\
\hline MS & Murashige and Skoog Medium \\
\hline MTBE & Methyl-Tertiary-Butyl Ether \\
\hline MTCC & Microbial Type Culture Collection \\
\hline MTPS & Monoterpene Synthase \\
\hline MTT & 3, [4, 5- dimethylthiazol, 2yl], 2, 5, diphenyl tetrazolium bromide \\
\hline MTPS & MonoTerPene Synthase \\
\hline MVA & Mevalonic Acid \\
\hline MW & Molecular Weight \\
\hline MWCO & Molecular Weight Cut Off \\
\hline NADB & NADP Binding \\
\hline NADPH & Nicotinamide Adenine Dinucleotide Phosphate \\
\hline $\mathrm{NCBI}$ & National Center for Biotechnology Information \\
\hline NCIM & National Collection of Industrial Microorganisms \\
\hline NIDDM & Non-Insulin-Dependent Diabetes Mellitus/ Type 2 Diabetes \\
\hline NIST & National Institute of Standards and Technology \\
\hline nkat & nano katal \\
\hline
\end{tabular}




\begin{tabular}{|c|c|}
\hline NMR & Nuclear Magnetic Resonance \\
\hline NO & Nitric Oxide \\
\hline $\mathrm{Nr}$ & non-redundant \\
\hline $\mathrm{nt}$ & nucleotide \\
\hline OD & Optical Density \\
\hline OECD & Organisation for Economic Co-operation and Development \\
\hline ON & Overnight \\
\hline ORD & Optical Rotatory Dispersion Spectroscopy \\
\hline ORF & Open Reading Frame \\
\hline OT & Old Tree \\
\hline PAL & L-Phenylalanine Ammonia Lyase \\
\hline PBS & Phosphate Buffer Saline \\
\hline PCR & Polymerase Chain Reaction \\
\hline PD & Parkinson's disease \\
\hline PDA & Potato Dextrose Agar \\
\hline PDB & Protein Data Bank \\
\hline PEG & Polyethylene Glycol \\
\hline $\mathrm{pH}$ & potenz Hydrogen \\
\hline PHYRE & Protein Homology/analogY Recognition Engine \\
\hline PIPES & L-piperazine-N-N-bis (2-ethane sulfonic) acid \\
\hline PMSF & PhenylMethylSulfonyl Fluoride \\
\hline POD & Peroxidase \\
\hline PPO & PolyPhenol Oxidase \\
\hline PROSITE & Protein Sites and Patterns \\
\hline PT & Prenyltransferase \\
\hline PUFA & PolyUnsaturated Fatty Acid \\
\hline PVPP & PolyVinyl Poly Pyrollidone \\
\hline $\mathrm{RBC}$ & Red Blood Cell \\
\hline Rf & Relative Front \\
\hline RLCCC & Rotary Locular Counter Current Chromatography \\
\hline RNase & RiboNuclease \\
\hline RNS & Reactive Nitrogen Species \\
\hline ROS & Reactive Oxygen Species \\
\hline RP-HPLC & Reverse Phase-High Pressure Liquid Chromatography \\
\hline RPMI & Roswell Park Memorial Institute \\
\hline rRNA & ribosomal RiboNucleic Acid \\
\hline RTP & Room Temperature $\left(25 \pm 3^{\circ} \mathrm{C}\right)$ and Pressure \\
\hline RT-PCR & Reverse Transcription-Polymerase Chain Reaction \\
\hline$S a$ & Santalum album \\
\hline SARM & Second Aspartate-Rich Motif \\
\hline SCOP & Structural Classification of Proteins \\
\hline SD & Seedling \\
\hline SD & Standard Deviation \\
\hline SDS-PAGE & Sodium Dodecyl Sulphate-PolyAcrylamide Gel Electrophoresis \\
\hline SE & Somatic Embryo \\
\hline SWO & SandalWood Oil \\
\hline SOD & Superoxide Dismutase \\
\hline
\end{tabular}




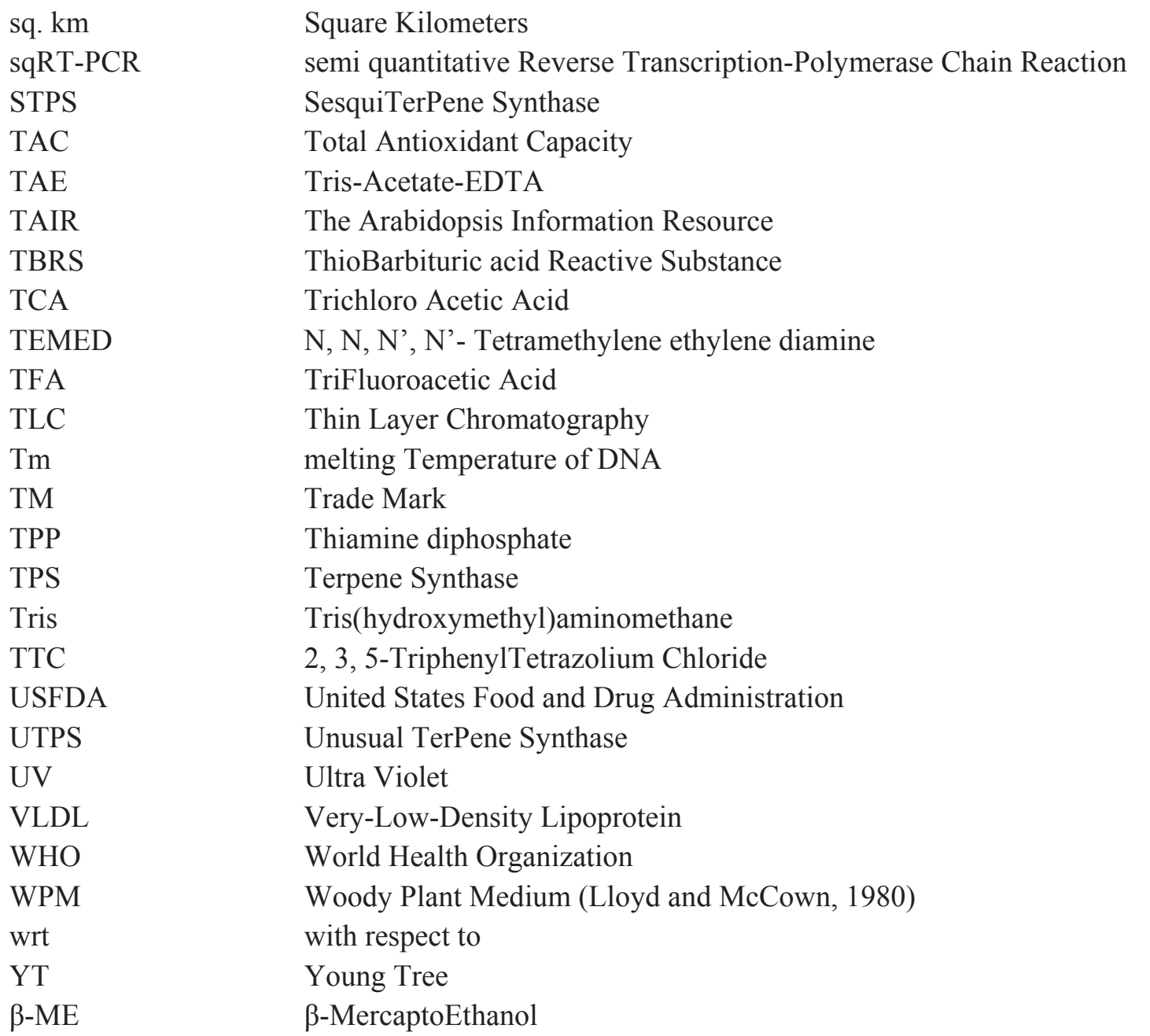

\section{LIST OF SYMBOLS}

$\begin{array}{ccc}\text { Amino acid } & \text { 1-Letter symbol } & \text { 3- Letter symbol } \\ \text { Alanine } & \mathrm{A} & \text { Ala } \\ \text { Arginine } & \mathrm{R} & \text { Arg } \\ \text { Asparagine } & \mathrm{N} & \text { Asn } \\ \text { Aspartic acid } & \mathrm{D} & \text { Asp } \\ \text { Cysteine } & \mathrm{C} & \text { Cys } \\ \text { Glutamic acid } & \mathrm{E} & \text { Glu } \\ \text { Glutamine } & \mathrm{Q} & \text { Gln } \\ \text { Glycine } & \mathrm{G} & \text { Gly } \\ \text { Histidine } & \mathrm{H} & \text { His } \\ \text { Isoleucine } & \mathrm{I} & \text { Ile } \\ \text { Leucine } & \mathrm{L} & \text { Leu } \\ \text { Lysine } & \mathrm{K} & \text { Lys } \\ \text { Methionine } & \mathrm{M} & \text { Met } \\ \text { Phenylalanine } & \mathrm{F} & \text { Phe } \\ \text { Proline } & \mathrm{P} & \text { Pro } \\ \text { Serine } & \mathrm{S} & \text { Ser } \\ \text { Threonine } & \mathrm{T} & \text { Thr } \\ \text { Tryptophan } & \mathrm{W} & \text { Trp } \\ \text { Tyrosine } & \mathrm{Y} & \text { Tyr } \\ \text { Valine } & \mathrm{V} & \text { Val }\end{array}$




\section{LIST OF TABLES}

Table 1.1 Major achievements in research and development work in sandalwood.

Table 1.2 Biological activities associated with sandalwood oil and molecules thereof.

Table 2.1 Chromatographic and spectral characteristics of phenolics detected in different sandalwood tissues fractions by RP- HPLC- DAD.

Table 2.2 LC- MS/ MS- based profiling of sandalwood phenylpropanoids.

Table 3.1 HPTLC- based metabolite profiling of sandalwood tissue sesquiterpenoid constituents.

Table 3.2 GC- based metabolite profiling of sandalwood tissue sesquiterpenoid constituents.

Table 3.3 GC- ITQ- MS analysis results obtained for volatile constituents from sandalwood tissues.

Table 3.4 Total terpenoid content from sandalwood tissues.

Table 3.5 Cross-reactivity of the polyclonal antibody.

Table 4.1 Physico- chemical and phytochemical analyses of extracts.

Table 4.2 Biological activities of sandalwood extracts.

Table 4.3 Investigated biochemical parameters in different mice groups for in vivo antioxidant activity of $\alpha$ - santalol and sandalwood oil.

Table 4.4 Investigated biochemical parameters in different mice groups for in vivo anti-hyperglycemic activity of $\alpha$ - santalol and sandalwood oil.

Table 4.5 Correlations between phytoconstituents and biological activities.

Table 5.1 GenBank genetic resource relevant to sandalwood research till date.

Table 5.2 The oligonucleotide (primer) sequences used for cloning the genes of interest.

Table 5.3 Table showing condition PCR conditions used for amplification of sesquiterpene synthase genes (STPS 1-3).

Table 5.4 Primers used in sq- RT- PCR reactions for amplification of 6 genes.

Table 5.5 Comparative bioinformatic analyses of PDB templates and obtained sandalwood clones.

Table 5.6 Important features of generated models by homology- based modeling and respective PDB templates.

Table 5.7 Comparison of overall quality factors between generated models by homology- based modeling and respective PDB templates.

Table 5.8 Relative tissue level expression profiling of sandalwood genes by sqRT- PCR. 


\section{LIST OF FIGURES}

Figure 1.1 Distribution of East Indian sandalwood in Indian subcontinent.

Figure 1.2 General phenylpropanoid biosynthetic pathway leading. to a wide range of phenylpropanoids and vascularization.

Figure 1.3 General terpenoid biosynthetic pathways operative in plants, with cross talk of intermediates. Sandalwood sesquiterpenoid biosynthetic pathway is highlighted.

Figure 1.4 Detailed MEP and MVA biosynthetic pathway, showing formation of various terpenoids and several pathway inhibitors.

Figure 1.5 Domain architecture of plant terpene synthases.

Figure 2.1 Schematic overview of the proposed investigation on profiling of phenylpropanoids.

Figure 2.2 Phenylpropanoid enzyme activities in sandalwood.

Figure 2.3 Levels of PP metabolites in sandalwood tissues.

Figure 2.4 Reverse phase high performance liquid chromatograms

(RP- HPLC) for the combined phenolic fractions of five tissues.

Figure 2.5 Occurrence of PPs in five sandalwood tissues.

Figure 2.6 Histochemical studies on PP accumulation, lignification and vascularization events in various growth/developmental stages.

Figure 2.7 Overall trends in biochemical, histochemical and enzymatic events in sandalwood in vitro and in vivo development.

Figure 3.1 Schematic representation of various approaches adopted in the investigation.

Figure 3.2 A. DXP synthase and B. HMGCoA reductase activities in sandalwood developmental stages.

Figure 3.3 Representative sesquiterpene synthase activity from callus.

Figure 3.4 Compositional analysis of sandalwood oil by HPTLC and $\mathrm{GC}$ analysis.

Figure 3.5 A. Typical representative TLC chromatogram for sandalwood oil constituents. B. GC- MS/ MS chromatogram for sandalwood oil, showing the two of the most abundant constituents, i.e., $\alpha$ - santalol and $\beta$ - santalol. C. GC- MS/ MS spectra for (Z)- $\alpha$ - santalol. D. GC- MS/ MS spectra for $(Z)-\beta$ - santalol.

Figure 3.6 HPTLC- based standard curve for $\alpha$-santalol.

Figure 3.7 Metabolite profiling of sandalwood tissues by HPTLC.

Figure 3.8 GC- based sesquiterpenoid profiling of sandalwood tissue sesquiterpenoid constituents.

Figure 3.9 Profiling of sandalwood volatile constituents by GC-MS/ MS in 5 developmental stages.

Figure 3.10 A. Chemical structures and $\log \mathrm{P}$ values of the farnesylated metabolites.

B. The absorption spectrum of farnesene, fanesol and FPP on HPTLC plates.

C. Representative HPTLC chromatograms. D. Quantification of farnesylated metabolites (C- 15, FPP, farnesene and farnesol) as detected by HPTLC.

Figure 3.11 Pigment quantification in sandalwood tissues, e.g., chlorophyll a content, chlorophyll b content, total chlorophyll, total carotenoids and total xanthophylls. 
Figure 3.12 A. Scheme showing purification of sesquiterpenoid from somatic embryo and the approaches followed. B. HPTLC- profile of combined organic somatic embryo extract.

79 inset same spectrum (unzoomed) to show the single peak.

82

82

Figure 3.18 The LC- APCI- MS (MS $\left.{ }^{2}\right)$ spectra for $(Z)$ - $\beta$ - santalol.

Figure 3.19 Preparative scale purification of $\alpha$ - santalol from sandalwood oil. A. RLCCC- aided separation of $Z$ - $\alpha$ - santalol and $Z$ - $\beta$ - santalol separation, B. silica- gel column chromatography, C. Sephadex LH20 ${ }^{\mathrm{TM}}$ aided separation and lastly, D. Preparative HPTLC- based purification of $\alpha$ - santalol. E. Purification events followed to obtain $\alpha$ - santalol from sandalwood oil.

Figure 3.20 A. UV- Vis spectrophotometric spectral scan for antigen, conjugate and carrier proteins. B. Spectrofluorimetric analysis for BSA and BSA- $\alpha$ - santalol conjugate.

C. SDS PAGE (15\%) analysis of carrier protein with and without conjugate.

Figure 3.22 Antibody production during the immunization period.

Figure 3.23 ELISA checkerboard results for determination of antibody titre against antigen.

Figure 3.24 A. Correlation between ELISA and HPTLC analysis methods for free $\alpha$-santalols. B. Standard curve generated against $\alpha$ - santalol, by TLC- immuno- dot blot, using polyclonal antibodies against $\alpha$ - santalol- BSA conjugate with anti - rabbit IgG goat- FITC labeled secondary antibody to aid in detection in UV light.

C. Immuno dot blot using a nitrocellulose strip for detection of $\alpha$ - santalol using rabbit polyclonal antibody against $\alpha$ - santalol- BSA conjugate.

D. Dipstick assay developed with toothpicks,

E. Immuno TLC dot blot for detection of $\alpha$ - santalol using the rabbit polyclonal antibody against $\alpha$ - santalol- BSA conjugate.

Figure 3.25 Affinity purification of polyclonal anti- $\alpha$ - santalol- BSA conjugate antibody using $4 \mathrm{CL}-\mathrm{B}^{\mathrm{TM}}$ matrix.

Figure 3.26 Confocal and bright field microscopy images for alpha- santalol and sesquiterpenoid localization in samples.

Figure 3.27 A. Sesquiterpene synthase (STPS) protein purification scheme followed. B. Gel filtration elution profile of pooled anion exchange elutes (250-500 mM KCl) run in a Superdex- 200 GF column.

C. $12 \%$ SDS- PAGE analysis of anion exchanger (Source Q 15) elutes.

D. $12 \%$ SDS- PAGE analysis of gel filtration (Superdex 200) elutes.

E. GC- chromatogram showing GC- based activity profiling of partially purified STPS, displaying production of santalols, santalenes and bergamotol from FPP.

Figure 3.28 Overview of terpenoids in various developmental stages in sandalwood. 
Figure 4.1 Schematic overview of the proposed investigation of biological activities.

Figure 4.2 A. HPTLC- based fingerprint of sandalwood extracts.

B. Cluster analysis (CA) of the metabolite compositions and biological activities for the 5 extracts of sandalwood.

Figure 4.3 Visual interpretation of the range of biological activities conducted with sandalwood extracts, sandalwood oil and positive controls.

Figure 5.1 Schematic representation of the proposed investigation.

Figure 5.2 Amplicons separated on $1.5 \%$ agarose gels, obtained by

PCR- based methods.

Figure 5.3 Restriction digestion analysis of TA- clones.

Figure 5.4 SaACT3 displaying the actin features, i.e., the profilin binding sites, the gelsolin binding sites and the ATP- binding sites.

Figure 5.5 Assignment of the translated SaCAD clone (3- 87 aa length) to the NADB- Rossman superfamily of proteins.

Figure 5.6 Assignment of the translated SaDXS1 clone to the TPP and transketolase- pyrophosphatase super family.

Figure 5.7 The SaSTPS3 is an isoprenoid biosynthetic superfamily gene showing a substrate binding pocket, a $\mathrm{Mg}^{2+}$ divalent metal ion binding site as well as the aspartate- rich regions.

Figure 5.8 Homology- based modeling of SaACT3, SaCAD and SaDXS2.

Figure 5.9 Homology- based modeling of SaFPPS, SaMTPS and SaSTPS3.

Figure 5.10 Semi quantitative RT- PCR measured expression levels of 6 genes in sandalwood tissues.

Box 1. Analytical methods for plant metabolite profiling and chromatographic fingerprinting.

Box 2. Assay schemes and methods for antioxidants. 


\section{LIST OF APPENDIX}

Appendix A.1 Drug- likeliness and physico- chemical and biological properties of $\alpha$-santalol. I

Appendix A.2 CAD genes characterized till date.

Appendix A.3 DXS genes characterized till date.

Appendix A.4 FPPS genes characterized till date.

Appendix A.5 Monoterpene synthases characterized till date.

Appendix A.6 Sesquiterpene synthases characterized till date.

Appendix B.1 Definitions of materials under study.

Appendix B.2 RP- HPLC- based acquisition of DAD spectra of up to 15 phenylpropanoids. VI

Appendix B.3 Representative LC- MS/ MS spectra in negative and positive modes, showing the presence of phenolics.

Appendix B.4 LC profile of the sandalwood tissue extracts.

Appendix C.1 Mice and rabbit immunization schemes. $\quad$ VIII

Appendix C.2 Identification of sesquiterpene synthase assay products from various tissues. VIII

Appendix C.3 Kovat's indices for santalanes and known sesquiterpenoids from sandalwood for polar and non- polar GC columns.

VIII

Appendix C.4 Sesquiterpenoid constituents in sandalwood oil as revealed by HPTLC and $\mathrm{GC}$ analysis.

Appendix C.5 Schemes, mechanisms and approaches followed for antibody development against $Z$ - $\alpha$ - santalol.

Appendix C.6 Schemes shown for antibody generation in mice and rabbits by two methods.

Appendix D.1 Methodology for phytochemical analyses of sandalwood extracts.

Appendix D.2 Correlations between groups of metabolites quantified. Group 1 and 2 represent the two groups of metabolites quantified and plotted against each other to obtain the correlation.

XII

Appendix D.3 Spectral characteristics of phytoconstituents in sandalwood extracts. XII

Appendix D.4 Percentage of each characterized metabolite groups in the tissue extracts.

XIII

Appendix D.5 MIC values $(\mu \mathrm{g} / \mathrm{ml})$ of sandalwood oil against 14 bacterial strains (both Gram +ve and Gram -ve) determined by the broth dilution method.

Appendix D.6 Antibacterial activity of tissue extracts based on disc diffusion method.

Appendix D.7 Agar spot detection method for antibacterial activity of the tissue extracts and sandalwood oil.

Appendix D.8 Antifungal activity of sandalwood oil against some plant pathogenic fungi and other laboratory strains.

IX

IX

$\mathrm{X}$

$\mathrm{XI}$

XIV

XIV

$\mathrm{XV}$

XV

Appendix D.9 TLC- bioautography of five extracts and sandalwood oil, against the 13 bacterial strains.

XVI

Appendix D.10 The TLC- bioautographic screening for tyrosinase inhibitors from sandalwood extractives and sandalwood oil.

XVII

Appendix D.11 The TLC- bioautographic screening for acetylcholinesterase and butyrylcholinesterase inhibitors from sandalwood extractives and sandalwood oil.

XVII

Appendix D.12 Allelopathic effects of sandalwood extracts and sandalwood oil against 10 plant species during seed germination.

XVII

Appendix D.13 Bacterial growth inhibition assays by germinating sandalwood seeds, against 8 various bacteria, with zones of inhibitions.

Appendix E.1 Multiple sequence alignment of homologous plant ACTs.

XVII

XVIII

XIX

$\begin{array}{lc}\text { Appendix E.3 Multi- alignment of nucleotide sequences of homologous plant DXSs. } & \text { XX } \\ \text { Appendix E.4 Multi- alignment of nucleotide sequences of homologous plant FPPSs. } & \text { XXI }\end{array}$

Appendix E.5 Multi- alignment of nucleotide sequences of homologous plant UTPSs. XXII

Appendix E.6 Multi- alignment of nucleotide sequences of homologous plant STPSs. XXIII

Appendix E.7 Sequence of the sandalwood actin genomic clone SaACT1. XXIV

Appendix E.8 Blast results obtained for actin genomic clone, SaACT1. XXIV 
Appendix E.9 Sequence of the sandalwood actin genomic clone SaACT2.

Appendix E.10 Blast results obtained for actin genomic clone, SaACT2.

$X X V$

Appendix E.11 Sequence of the sandalwood actin genomic clone SaACT3.

XXV

Appendix E.12 Blast results obtained for actin genomic clone, SaACT3.

XXVI

Appendix E.13 Comparison of the three different actin clones

(SaACT1, SaACT2, SaACT3) obtained from sandalwood tissues.

XXVI

Appendix E.14 Sequence of the sandalwood CAD genomic clone SaCAD.

Appendix E.15 Blast results obtained for the CAD genomic clone, SaCAD.

XXVI

Appendix E.16 Sequence of the sandalwood DXS genomic clone SaDXS1.

XXVI

Appendix E.17 Blast results obtained for the first DXP synthase genomic clone, SaDXS1.

XXVII

Appendix E.18 Sequence of the sandalwood DXS genomic clone SaDXS2.

Appendix E.19 Blast results obtained for the second DXP synthase genomic clone, SaDXS2.

Appendix E.20 Comparison of the two deoxy- xylulose phosphate synthase clones (SaDXS1 and SaDXS2) from sandalwood.

Appendix E.21 Sequence of the sandalwood FPPS genomic clone SaFPPS.

Appendix E.22 Blast results obtained for the farnesyl pyrophosphate synthase genomic clone, SaFPPS.

Appendix E.23 Sequence comparisons among sandalwood SaFPPS with other plant FPPS homologues.

Appendix E.24 Sequence of the sandalwood monoterpene synthase genomic clone SaMTPS.

Appendix E.25 Blast results obtained for the monoterpene synthase genomic clone, SaMTPS.

XXVII

XXVIII

XXVIII

XXVIII

XXVIII

XXVIII

XXIX

XXIX

XXIX

XXX

Appendix E.26 Sequence of the sandalwood STPS genomic clone SaSTPS1.

$\mathrm{XXX}$

Appendix E.27 Blast results obtained for the first sesquiterpene synthase genomic clone, SaSTPS1.

Appendix E.28 Sequence of the sandalwood STPS genomic clone SaSTPS2.

Appendix E.29 Blast results obtained for the second sesquiterpene synthase genomic clone, SaSTPS2.

Appendix E.30 Sequence of the sandalwood STPS genomic clone SaSTPS3.

Appendix E.31 Blast results obtained for the third sesquiterpene synthase genomic clone, SaSTPS3.

Appendix E.32 Comparison of the three SaSTPS clones obtained from sandalwood among other plant sesquiterpene synthase sequences aligned from GenBank sequences.

Appendix E.33 Multiple sequence alignment of homologous plant ACTs.

Appendix E.34 Multiple sequence alignment of homologous plant CADs.

Appendix E.35 Multiple sequence alignment of homologous plant DXSs.

Appendix E.36 Multiple sequence alignment of homologous plant FPPSs.

Appendix E.37 Multiple sequence alignment of homologous plant MTPSs.

Appendix E.38 Multiple sequence alignment of homologous plant STPSs.

Appendix E.39 Phylogenetic analysis of plant ACTs.

Appendix E.40 Phylogenetic analysis of plant CADs.

Appendix E.41 Phylogenetic analysis of plant DXSs.

Appendix E.42 Phylogenetic analysis of plant FPPSs.

$\mathrm{XXX}$

$\mathrm{XXX}$

XXXI

XXXI

Appendix E.43 Phylogenetic analysis of plant MTPSs.

Appendix E.44 Phylogenetic analysis of plant STPSs.

Appendix E.45 Vector map of pTZ57R/ T (MBI, Fermentas) used for TA- cloning.

XXXIII

XXXIV

XXXV

XXXVI

XXXVI

XXXVII

XXXVIII

XXXIX

$\mathrm{XL}$

XLI

XLII

XLIII

XLIII

Appendix F.1 Compostion of the MS (Murashige and Skoog, 1962) medium used in the investigation to raise in vitro developmental stages.

XLIV

Appendix F.2 Compostion of the WPM (Lloyd and McCown, 1980) used in the investigation to raise in vitro developmental stages.

XLIV

XLV

Appendix F.3 Flowchart showing the Harborne protocol (Harborne, 1998).

Appendix F.4 Proposed sandalwood sesquiterpenoid biosynthetic pathway schemes (modified from Sell, 2003). 


\section{GLOSSARY}

Antioxidants- Protect the body against free radicals by neutralizing, reducing or scavenging the oxidants before they can damage cells, tissues, DNA, lipids and proteins (Sanchez-Moreno, 2002).

Bioprospecting- The search for and examination of biological resources (plants, animals, microorganisms) that have features that might be of value for commercial development; is the search for useful biological materials [i.e, non human biological materials (NHBMs) in common pool resources (CPRs)] (Polski, 2005); the purposeful evaluation of wild biological material in search of valuable new products, has always been a central activity in human development; involves the application of advanced technologies to develop new pharmaceuticals, agrochemicals, cosmetics, flavorings, fragrances, industrial enzymes, and other products from biodiversity (Artuso, 2002).

Chromatographic Fingerprinting- Method to show chemical information of medicines or herbals with chromatograms, spectrograms and such graphical means of chemical analytical techniques allowing visual inspection of chromatographic fingerprint as identification.

Condensed Tannins/ Pro (antho) cyanidins/ Oligomeric Proanthocyanidins- Polymers of 2 to 50 (or more) flavonoids, such as catechins that are joined by carbon-carbon bonds, which are not susceptible to being cleaved by hydrolysis.

Enzymatic antioxidant defense-superoxide dismutase (SOD), glutathione peroxidase (GPx), catalase (CAT) etc.

Flavan-3-ols/ Flavanols- A class of flavonoids having a 2- phenyl-3, 4-dihydro- 2Hchromen-3-ol skeleton, and are building blocks of proanthocyanidins. Examples: catechins.

Free Radicals- Chemical species that contain one or more unpaired electrons, are capable of independent existence, are highly unstable and reactive thus cause damage to other molecules by extracting electrons from them in order to attain stability (SanchezMoreno, 2002).

Metabolic Fingerprinting- Rapid and global analysis for classification of samples on the basis of provenance of either their biological relevance or origin (Fiehn, 2001).

Metabolite / Metabolic Profiling- Analysis focused on a group of metabolites, for example, a class of compounds such as carbohydrates, amino acids or those associated with a specific pathway (Fiehn, 2001). 
Metabolite Target Analysis- Analysis restricted to metabolites of, for example, a particular enzyme system that would be directly affected by abiotic or biotic perturbation (Fiehn, 2001).

Metabolome- Defined as the complete complement of all small molecule $(<1500 \mathrm{Da})$ metabolites found in a specific cell, organ or organism.

Metabolomics- Comprehensive qualitative and quantitative analysis of all metabolites simultaneously under a given set of conditions (Fiehn, 2001).

Metabonomics- Quantitative measurement of the dynamic multi-parametric metabolic response of living systems to pathophysiological stimuli or genetic modification (Nicholson et al., 2002).

Non-enzymatic Antioxidant Defense-ascorbic acid (vitamin C), $\alpha$-tocopherol (vitamin E), glutathione (GSH), carotenoids, flavonoids, etc.

Polyphenols- A group of chemical substances found in plants, characterized by the presence of more than one phenol unit or building block per molecule. Polyphenols are generally divided into hydrolyzable tannins (gallic acid esters of glucose and other sugars) and phenylpropanoids, such as lignins, flavonoids, and condensed tannins

Quinones- Compounds having a fully conjugated cyclic dione structure derived from aromatic compounds by conversion of an even number of $-\mathrm{CH}=$ groups into $-\mathrm{C}(=\mathrm{O})$ groups with any necessary rearrangement of double bonds. Example: benzoquinone, phylloquinone etc.

Reactive Nitrogen Species (RNS)- nitric oxide (NO), peroxynitrite.

Reactive Oxygen Species (ROS)- superoxide anion, peroxyl, hydrogen peroxide $\left(\mathrm{H}_{2} \mathrm{O}_{2}\right)$ and hydroxyl radicals $\left(\mathrm{OH}^{\cdot}\right)$.

Tannins- Astringent, bitter plant polyphenols that precipitate proteins and are divided into hydrolyzable tannins [i.e., gallic acid] and condensed tannins/ proanthocyanidins [i.e., flavones].

\section{TERMINOLOGY}

Callus (CA): In vitro grown highly proliferating cell line (IITKGP/ 91), grown on solid MS/ WPM media, supplemented with 2, 4- D (1 mg/ 1), 14 days old.

Somatic Embryo (SE): In vitro grown embryos from somatic cells, grown on solid MS/ WPM media, supplemented with IAA $(0.5 \mathrm{mg} / 1)$ and BAP $(0.5 \mathrm{mg} / 1), 2$ weeks old.

Seedling (SD): In vitro grown somatic seedlings, grown on solid MS/ WPM media supplemented with IAA (1 mg/ 1), IBA (1 mg/1) and GA (0.5 mg/ 1), 6 weeks old.

Young Tree (YT): Field grown tree growing in the backyard of BT, IIT Kgp, non- oil producing tree, mostly vegetative twigs sampled, 7 years old.

Old Tree (OT): Field grown tree growing in the backyard of BT, IIT Kgp, oil producing tree, mostly vegetative twigs sampled, 14 years old. 


\begin{abstract}
The East Indian Sandalwood, Santalum album L., a tropical woody tree, deposits sesquiterpenoid rich essential oil in the heartwood. In view of its century-old traditional uses in perfumery and healthcare this investigation in prospecting of phenylpropanoid and terpenoids from in vitro tissues, in comparison to the in vivo trees, was undertaken to throw light on the phytochemistry of the healthcare molecules, explore in vitro tissues as alternate avenues for the supply and profiling of metabolites as a pre-requisite towards future sesquiterpenoid biosynthetic studies in this plant.

Important phenylpropanoid enzymes i.e., phenylalanine ammonia lyase (PAL), cinnamyl alcohol dehydrogenase (CAD) and lignin peroxidases (POX) and their products, i.e., phenolic, hydroxycinnamic and benzoic acid, flavonoid, anthocyanin and lignin contents showed concomitant increase with lignification/ vascularization as visualized with histochemical analyses. HPLC analysis revealed identities and quantities of 20 phenolics, whereas LC-MS analysis identified $\sim 52$ phenylpropanoids through out development.

Differential accumulation of terpenoid biosynthetic pathway enzymes, i.e., DXP synthase, HMGCoA reductase and sesquiterpene synthase and metabolites i.e., sesquiterpenoid hydrocarbons and alcohols, photosynthetic pigments and farnesylated intermediates were evident from GC and HPTLC analyses. A putative sesquiterpene synthase $(\sim 60 \mathrm{kDa})$ was partially purified from leaves. GC-MS/ MS studies revealed the presence of $\sim 47$ volatile constituents in sandalwood. The fragrant sandalwood oil constituent, $\beta$-santalol was isolated from somatic embryos and characterized by ${ }^{13} \mathrm{C}$ NMR, ESI-MS, LC-APCI-MS, MALDI-ToF, GC-MS/ MS and FTIR analyses whereas the bioactive constituent $\alpha$-santalol, bulk-purified from sandalwood oil by HPTLC, RLCCC and column chromatography.

Tissue extracts rich in terpenoids and phenylpropanoids revealed antimicrobial, antioxidant, $\alpha$-amylase inhibition, anti-tyrosinase and neuroprotective potentials in vitro. Sandalwood oil and $\alpha$-santalol showed strong in vivo antioxidant and anti-hyperglycemic potentials.

Homology-based cloning using degenerate primers, yielded partial clones of a housekeeping gene (actin), a phenylpropanoid gene (CAD) and 4 terpenoid biosynthetic pathway genes (DXP synthase, FPP synthase, monoterpene synthase and sesquiterpene synthase), that showed homology and phylogenetic relationships with other plant genes. Homology-based modeling revealed their protein structure-function relationships, i.e., catalytic sites, domains and motifs. Structures were validated by Ramachandran plots. Transcriptional profiling by sqRT-PCR revealed higher expression levels of five transcripts in callus and young tree.
\end{abstract}

Keywords: Sandalwood, Santalum album L., prospecting, phenylpropanoid, sesquiterpenoid, santalol, terpene synthase, bioactivity. 


\section{CONTENTS}

Pages

Title Page

Certificate of Approval

\section{i}

Certificate by Supervisor

iii

$\mathrm{V}$

Declaration vii

Preface ix

Acknowledgement $\quad$ xi

List of Abbreviations xiii

List of Tables $\quad$ xix

List of Figures xxi

List of Appendix $\quad$ xxv

Glossary xxvii

Abstract $\quad$ xxix

Chapter 1 Introduction, Review of the Literature and Objectives of the Present Investigation

1.1 Introduction

1.2 Review of literature

1.2.1 Taxonomy 2

1.2.2 Diseases and pests 3

1.2.3 Sandalwood essential oil 3

1.2.4 Santalenes as major constituents 3

1.2.5 Chemo- synthesis of santalenes 4

1.2.6 Synthetic analogues of santalanes 4

1.2.7 Sandalwood odor chemistry $\quad 5$

1.2.8 Organoleptics and physicochemical properties 5

1.2.9 Santalol biosynthetic pathway 5

1.2.10 In vitro micropropagation and plant development 7

1.2.11 Secondary metabolism in plants $\quad 7$

1.2.12 Plant cell cultures as sources of natural products 7

1.2.13 Approaches to characterize secondary metabolome $\quad 8$

$\begin{array}{ll}\text { 1.2.14 Phenylpropanoid biosynthetic pathway } & 10\end{array}$

$\begin{array}{ll}\text { 1.2.14.1 Phenylalanine ammonia lyase (PAL) } & 10\end{array}$

$\begin{array}{ll}\text { 1.2.14.2 Cinnamyl alcohol dehydrogenase (CAD) } & 10\end{array}$

1.2.14.3 Peroxidase (POX) 11

1.2.14.4 Polyphenol oxidase (PPO) 11

1.2.14.5 Phenolics 11

1.2.14.6 Lignin biosynthesis and lignification $\quad 13$

1.2.14.7 Flavonoids and anthocyanins 13

1.2.14.8 Phenylpropanoids in heartwood $\quad 14$

1.2.15 Terpenoids $\quad 15$

1.2.15.1 Importance of terpenoids $\quad 15$

1.2.15.2 Terpenoid biosynthetic pathway $\quad 15$

1.2.15.3 Terpenoid production in vitro 16

1.2.15.4 Chlorophylls and carotenoids $\quad 17$

1.2.15.5 1- deoxy- D- xylulose phosphate synthase (DXS) 18

1.2.15.6 3- Hydroxy- 3- methylglutaryl- coenzyme A reductase (HMGCoAR) 19

1.2.15.7 Farnesyl diphosphate synthase (FPPS) 19

$\begin{array}{ll}\text { 1.2.15.8 Terpene synthase (TPS) } & 19\end{array}$

1.2.15.9 Monoterpene synthase (MTPS) 20 
1.2.15.10 Sesquiterpene synthases (STPS)

1.2.16 Biological activities of natural products 22

1.2.16.1 Essential oils as bioactives 22

1.2.16.2 Phytoconstituents as antimicrobials 22

1.2.16.3 Phytoconstituents as antioxidants $\quad 22$

1.2.16.3.1 Phenylpropanoids as antioxidants 23

1.2.16.4 Phytoconstituents as tyrosinase inhibitors $\quad 24$

1.2.16.5 Phytoconstituents as antidiabetic principles 25

1.2.16.5.1 Diabetes mellitus 25

1.2.16.5.2 Hypoglycemic potential of plants 26

1.2.16.6 Cholinesterase inhibitors as neuroprotective agents 26

$\begin{array}{ll}\text { 1.2.16.7 Phytoconstituents as cytotoxic agents } & 27\end{array}$

1.2.16.8 Anticancer drugs from plants $\quad 27$

1.2.16.9 Phytoconstituents as MMP inhibitors $\quad 27$

1.2.17 Research and development work in sandalwood 28

1.3 Objectives of the investigation 29

Chapter 2 Profiling of Phenylpropanoids 31

2.1 Introduction 31

2.2 Materials and methods $\quad 32$

2.2.1 Preparation of crude enzyme extracts $\quad 32$

2.2.2 Enzyme assays $\quad 32$

2.2.2.1 Phenylalanine ammonia- lyase (PAL, EC 4.3.1.5) assay 32

2.2.2.2 Cinnamyl alcohol dehydrogenase (CAD, EC 1.1.1.195) assay 32

2.2.2.3 Peroxidase (POX, EC 1.11.1.7) assays 33

2.2.3 Polyphenol oxidase (PPO) (EC 1.14.18.1) enzyme preparation
and assay

2.2.4 Profiling of phenylpropanoids $\quad 34$

2.2.4.1 Isolation of free and wall- bound phenolics 34

2.2.4.2 Folin- Ciocalteau assay for phenolics 34

2.2.4.3 High Pressure Liquid Chromatography (HPLC) analysis of phenolics 34

2.2.4.4 Liquid Chromatography Mass Spectroscopy (LC- MS) analyses of
phenylpropanoids

2.2.4.5 Anthocyanin quantification 36

2.2.4.6 Flavonoid quantification 36

2.2.4.7 Concentrations of total UV- absorbing compounds 36

2.2.4.8 Quantification of lignin 36

2.2.4.9 Quantification of shikimic acid 37

2.2.5 Microscopy and histochemistry 37

2.2.5.1 Fluorescent microscopy studies 37

2.2.5.2 Wesner reaction for lignification 37

2.2.5.3 Maule reaction for lignification 38

2.2.5.4 Double staining for visualization of soft and hard tissues 38

2.2.5.5 Polychromatic staining by Toluidine Blue O 38

$\begin{array}{ll}2.2 .6 & \text { Data analysis } \\ 28\end{array}$

2.3 Results $\quad 38$

2.3.1 Phenylpropanoid enzymes 38

2.3.2 Phenylpropanoid metabolites $\quad 39$

2.3.3 RP- HPLC and LC- MS/ MS based profiling of phenylpropanoids 41

2.3.4 Histochemical evidences for differentiation and maturation events $\quad 45$

2.4 Discussion $\quad 47$

Chapter 3 Profiling of Terpenoids

3.1 Introduction $\quad 55$ 
3.2 Materials and methods

56

3.2.1 Extraction of enzymes involved in terpenoid biosynthesis

3.2.2 3- Hydroxy- 3- methylglutaryl coenzyme A reductase, (HMGCoAR, EC 1.1.1.34) assay

3.2.3 1- deoxy- D- xylulose 5- phosphate synthase (DXS, EC 2.2.1.7) assay

3.2.4 Sesquiterpene synthase (STPS, EC 4.2.3.41 ?) assay

3.2.4.1 Extraction of sesquiterpene synthase enriched crude fractions

3.2.4.2 Sesquiterpene synthase (STPS) assay

3.2.5 Profiling of sesquiterpenoids

3.2.5.1 Extraction of sesquiterpenoids from tissues

3.2.5.2 Thin layer chromatography (TLC) and high performance thin layer chromatography (HPTLC) analysis of tissue extracts and sandalwood oil

3.2.5.3 Gas chromatography (GC) analyses of sandalwood oil and tissues

3.2.5.4 Quantification of total terpenoids in tissues

3.2.6 Quantification of sesquiterpenoid biosynthesis intermediates

3.2.6.1 Extraction of farnesylated compounds

3.2.6.2 Preparation of standard farnesylated compounds

3.2.6.2.1 Extraction of acid phosphatase (APase) rich fractions from potato

3.2.6.2.2 Acid phosphatase assay

3.2.6.2.3 Enzymatic hydrolysis of prenylpyrophosphates

3.2.6.3 HPTLC- based analyses for detection and quantification

3.2.7 Quantification of chlorophylls, carotenoids and xanthophylls

3.2.8 Purification and characterization of $\beta$ - santalol from somatic embryos

3.2.8.1 Extraction and purification of $\beta$ - santalol

3.2.8.2 Nuclear Magnetic Resonance (NMR) analysis

3.2.8.3 Matrix Assisted Laser Desorption Ionization- Time of Flight Mass Spectrometry (MALDI- ToF- MS) analysis

3.2.8.4 Electron Spray Ionization Mass Spectroscopy (ESI- MS) analysis

3.2.8.5 Fourier Transform Infrared Spectroscopy (FTIR) analysis

3.2.8.6 Gas Chromatography Mass Spectroscopy (GS- MS/ MS) analysis

3.2.8.7 Liquid Chromatography- Atmospheric Pressure Chemical IonizationMass Spectroscopy (LC- APCI- MS/ MS) analysis

3.2.9 Purification of $\alpha$-santalol from sandalwood oil

3.2.9.1 Rotatory locular counter current chromatography (RLCCC)

3.2.9.2 Column chromatography

3.2.10 Immunodetection of $\alpha$ - santalol

3.2.10.1 Polyclonal antibodies against $\alpha$ - santalol

3.2.10.2 Antigen ( $\alpha$ - santalol- BSA conjugate) preparation

3.2.10.2.1 Method 1

3.2.10.2.2 Method 2

3.2.10.3 Confirmation of conjugation of BSA- $\alpha$ - santalol

3.2.10.3.1 UV- visible spectrophotometry

3.2.10.3.2 Spectroflourimetry

3.2.10.3.3 SDS PAGE analysis

3.2.10.3.4 MALDI- ToF- MS analysis

3.2.10.4 Raising antibodies in mice and rabbit

3.2.10.4.1 Immunization of rabbits

3.2.10.4.2 Immunization of mice

3.2.10.4.3 Antisera titer determination by indirect ELISA

3.2.10.5 Standard curve generation for $\alpha$ - santalol using antibody

3.2.10.6 Immunodetection of $\alpha$ - santalol on solid surface

3.2.10.7 Immuno TLC- Dot Blot assay (DAB- based detection system)

3.2.10.8 Immuno Dot Blot assay (FITC- based detection system)
56

56

56

56

56

57

57

57

58

58

59

59

59

59

59

60

60

60

60

60

60

60

61

61

61

61

62

62

63

63

63

63

63

63

63

64

64

64

64

64

65

65

66

66

66

67 
3.2.10.10 Dip- stick ELISA (wooden toothpicks)

3.2.10.11 Polyclonal antibody ( $\operatorname{IgG})$ purification by affinity chromatography

3.2.10.12 Immunohistolocalization of $\alpha$ - santalol

3.2.10.12.1 Localization of $\alpha$ - santalol by confocal laser scanning microscopy (CLSM)

3.2.10.12.2 Histochemical localization of santalols

3.2.11 Purification of sesquiterpene synthase from leaf $\quad 69$

3.2.11.1 Extraction of crude proteins $\quad 69$

$\begin{array}{ll}\text { 3.2.11.2 Anion exchange chromatography } & 69\end{array}$

3.2.11.3 Gel filtration chromatography $\quad 69$

$\begin{array}{ll}3.3 \text { Results } & 70\end{array}$

3.3 Terpenoid biosynthesis enzymes $\quad 70$

3.3.1 DXS and HMGCoAR enzyme activities $\quad 70$

3.3.1.2 Sesquiterpene synthase assay and GC- based identification of products $\quad 70$

3.3.2 Profiling of sesquiterpenoids $\quad 71$

3.3.2.1 Sesquiterpenoid composition of the sandalwood oil 71

3.3.2.2 Sesquiterpenoid composition of sandalwood (HPTLC- based) 73

3.3.2.3 Sesquiterpenoid composition of the sandalwood tissues (GC- based) 74

3.3.2.4 GC- MS/ MS- based profiling of sandalwood volatile constituents $\quad 75$

3.3.2.5 Farnesylated compounds in sandalwood (HPTLC- based) 76

3.3.2.6 Terpenoid content $\quad 78$

3.3.2.7 Photosynthetic pigments in sandalwood $\quad 78$

3.3.3 Purification of $\beta$ - santalol from somatic embryo $\quad 79$

3.3.3.1 Confirmation of $(Z)$ - $\beta$ - santalol by ${ }^{13} \mathrm{C}$ - NMR, MALDI- ToF- MS, FTIR, GC- MS/ MS and LC- APCI- MS/ MS analyses 80

3.3.4 Isolation of $(Z)-\alpha$ - santalol $\quad 83$

3.3.4.1 Preparative- scale purification of $(Z)$ - $\alpha$ - santalol by column
chromatography, RLCCC and HPTLC

3.3.5 Immunodetection of $Z$ - $\alpha$ - santalol $\quad 84$

3.3.5.1 Immunogen design $\quad 84$

3.3.5.2 Confirmation of conjugation of $\alpha$ - santalol to BSA 84

3.3.5.2.1 UV- vis spectrophotometry $\quad 84$

$\begin{array}{ll}\text { 3.3.5.2.2 Spectroflourimetry } & 84\end{array}$

3.3.5.2.3 SDS- PAGE analysis $\quad 85$

3.3.5.2.4 MALDI- ToF- MS analysis $\quad 85$

3.3.5.3 Production of polyclonal antibodies $\quad 86$

3.3.5.4 Optimization of antibody and $\alpha$ - santalol- BSA conjugate concentrations 86

3.3.6 Immunolocalization of $(Z)-\alpha$ - santalol in sandalwood developmental stages by confocal laser scanning microscopy (CLSM) 88

3.3.7 Partial purification of sesquiterpene synthase (SaSTPS) protein $\begin{array}{lr}\text { from sandalwood leaves } & 90 \\ \text { 3.4 Discussion } & 92\end{array}$

Chapter 4 Screening of Biological Activities of Extracts Rich in Phenylpropanoids and Terpenoids 101

$\begin{array}{ll}4.1 \text { Introduction } & 101\end{array}$

$\begin{array}{ll}\text { 4.2 Materials and Methods } & 103\end{array}$

4.2.1 Microorganisms 103

4.2.1.1 Bacterial strains $\quad 103$

4.2.1.2 Fungal strains $\quad 103$

4.2.2 Physical characterization of the tissues and extracts 103

4.2.2.1 Dry weight, moisture and ash content 103

4.2.2.2 Preparation of extracts 103 
4.2.2.3 $\mathrm{pH}$ of the extracts

4.2.2.4 Determination of plant extract yield

4.2.3 Phytochemical profiling of extracts

104

4.2.3.1 High performance thin layer chromatography (HPTLC) analysis

104

4.2.4 Biological activity screening of the extract

104

4.2.4.1 Minimum inhibitory concentration (MIC) determination 104

4.2.4.2 Disc- diffusion method for antibacterial activity 105

4.2.4.3 Agar spot method for antibacterial activity 105

4.2.4.4 TLC bioautography for antibacterial screening 105

4.2.4.5 Quantitative evaluation of antimicrobial activity 105

4.2.4.6 Antifungal activity by disc diffusion method 105

4.2.4.7 Lipid peroxidation inhibition in mice liver and brain microsomes

(TBA method)

4.2.4.8 Reducing power determination

106

106

4.2.4.9 Hydroxyl radical scavenging activity (deoxyribose method) 106

4.2.4.10 Metal (ferrous) ion chelating activity

106

4.2.4.11 Ferric reducing antioxidant power (FRAP) assay 106

4.2.4.12 Total antioxidant capacity (TAC) 106

4.2.4.13 $\beta$ - carotene linoleate bleaching activity 106

4.2.4.14 Nitric oxide free radical scavenging activity 106

4.2.4.15 ABTS free radical scavenging activity 106

4.2.4.16 DPPH free radical scavenging activity 107

$\begin{array}{ll}\text { 4.2.4.17 DPPH dot blot (qualitative) assay } & 107\end{array}$

4.2.4.18 Tyrosinase inhibition (spectrophotometric) 107

4.2.4.19 Tyrosinase inhibition (bioautography) 107

4.2.4.20 Alpha- amylase (EC 3.2.1.1) inhibition assay (spectrophotometric) 107

4.2.4.21 Alpha- amylase inhibition assay (disc- diffusion) 108

$\begin{array}{ll}\text { 4.2.4.22 Glucose diffusion inhibition assay } & 108\end{array}$

4.2.4.23 Cholinesterase (ChE) inhibition assay (TLC bioautographic) 108

4.2.4.24 Cholinesterase (ChE) inhibition assay (spectrophotometric) 108

4.2.4.25 MMP inhibition assay 108

4.2.4.26 Cytotoxicity screening in fibroblast cell lines 109

4.2.4.27 Cytostatic potential in carcinoma and melanoma cell lines 109

4.2.4.28 In vivo anti- hyperglycemic assay in alloxan- induced diabetic mice model

4.2.5.28.1 Experimental animals 109

4.2.5.28.2 Administration of compounds to normal mice 109

$\begin{array}{ll}\text { 4.2.5.28.3 Preparation of diabetic mice } & 110\end{array}$

4.2.5.28.4 Estimation of blood glucose level 110

4.2.5.28.5 Estimation of liver glycogen content 110

4.2.5.28.6 Estimation of serum bilirubin level determination $\quad 110$

4.2.5.29 In vivo antioxidant assay 110

4.2.5.29.1 Preparation of oxidative stress induced mice 111

4.2.5.29.2 SGPT/ ALT (Alanine Aminotransferase- Serum
Glutamate Pyruvate Transminase- E.C.2.6.1.2) assay

4.2.5.29.3 SGOT/ AST (Aspartate Aminotransferase- Serum
Glutamate Oxaloacetate Transminase- E.C.2.6.1.1) assay

4.2.5.29.4 Serum alkaline phosphatase (ALP) assay 111

4.2.5.29.5 Serum bilirubin level determination $\quad 111$

4.2.5.29.6 Superoxide dismutase activity 111

$\begin{array}{ll}\text { 4.2.5.29.7 Catalase activity } & 111\end{array}$

4.2.5.29.8 Free sulfhydryl groups in serum as reduced glutathione (GSH) $\quad 112$

4.2.5.29.9 Quantification of protein carbonyl content 112

4.2.5.29.10 NO assay (for nitrite determination) 112 
4.2.5.29.11 Serum antioxidant activity (DPPH) based

4.2.5.30 Splenocyte (spleen lymphocyte) and macrophages (activated monocytes) isolation

112

112

113

4.2.5.32 Nitrite determination ( $\mathrm{NO}$ assay) in macrophages

113

113

113

113

114

114

114

116

116

117

4.3.3.2 Antioxidant, antityrosinase, antidiabetic and neuroprotective potentials

4.3.3.3 Cytotoxicity in fibroblasts and cancer cell lines, NO production in macrophages and MMP inhibition in vitro

Chapter 5 PCR- based Cloning and Evaluation of Phenylpropanoid and Terpenoid Biosynthetic Pathway Genes

5.2.4.4 Polymerase chain reaction (PCR) amplification

5.2.4.5 Reverse transcriptase- polymerase chain reaction (RT- PCR) $\begin{array}{ll}\text { and complimentary DNA (cDNA) preparation } & 139\end{array}$

5.2.4.6 Gradient PCR 
5.3.6 Partial clones of sesquiterpene synthase (STPS)

5.3.7 Phylogenetic analysis of the clones

5.3.8 Bioinformatic analysis, homology- based modeling and structurefunction relationships of the proteins

5.3.9 Tissue level expression profiling of the 6 genes 156

5.4 Discussion

156

Chapter 6 Conclusions and Future Scope

163

6.1 Conclusions

163

6.2 Future Scope

165

References

167

Appendix

In CD

Curriculum vitae 
Chapter 1

Introduction, Review of the Literature and Objectives of the Present Investigation 


\subsection{Introduction}

The East Indian Sandalwood, Santalum album L., is a tropical, woody and perennial essential oil yielding tree. The fragrant heartwood accumulates the sandalwood oil (SWO), rich in sesquiterpenoids and is reported to have many medicinal properties. Epidemic phytoplasmal 'spike' disease leading to severe destruction, illegal poaching and over exploitation owing to increased global demand are the reasons of it being inducted into IUCN, Red List of Threatened Species (IUCN, 2006) as vulnerable, thus necessitating its in vitro micropropagation and biotechnological manipulation. The Santalum album wood and oil (rich in sesquiterpenoid santalols) are among the costliest plant products (wood $\sim$ US $\$ 180 \mathrm{~kg}^{-1}$; oil $\sim$ US $\$ 26001^{-1}$ ). The estimated average global annual export is about 2, 000 tons of wood and 100 tons of oil (Gupta, 1998), against a projected demand of 10, 000 tons of wood, involving an international trade of about US \$ 360 million; thus implying a huge gap between demand and supply, largely due to dwindling natural population of the plant. In USA alone the total

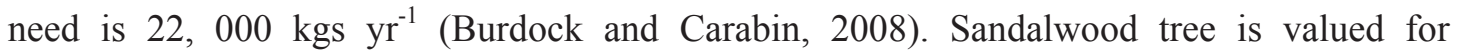
commercial, medicinal, traditional, spiritual, aesthetic and social importance. The traditional curative properties for acne, urino- genital tract infections, bronchitis, congestion etc. are known.

The number of plant species in India is estimated to be over 45, 000 representing about $7 \%$ of the world's flora. Medicinal plants, as a group, comprise approximately 8, 000 species and account for about $50 \%$ of all the higher flowering plant species of India. India is one of the richest countries in the world as regards genetic resource of medicinal and aromatic plants. It constitutes $11 \%$ of the total known world flora having medicinal properties (http:// www. inheritanceindia.co.in). The commercial, traditional and social importances of this medicinal tree are:

1. Cosmetics, perfumes, soaps, musks, face packs for its fragrance, fixative property and its oil base fixes both dry and oily skin.

2. Handicrafts, luxury items and wooden furniture for domestic use due to durability and scent.

3. The unique fragrance of the oil is known as an aid to meditation, spiritual growth, emotionally it relaxes stress, soothes irritation, lifts depression and is aphrodisiac.

4. It has a long history in ethno pharmacology in India and elsewhere, for uses such as a tonic to the immune system, effective against strep throat, gastrointestinal ailments, skin infections, reducing vomiting, fever, thirst and so on, though the perfumery use has outweighed the medicinal uses. 
No active principles were implicated in such healthcare purposes. However, in the last decade, the compounds from oil were shown to have antimicrobial, anticancer and antiviral properties. The above facts inspired us to the present study on bioprospecting of the phenylpropanoids and terpenoids. Apart from the healthcare angle, the accumulation of the oil in the heartwood in this plant generates natural curiosity of correlating the profiles of phenylpropanoids and terpenoids.

\subsection{Review of literature}

\subsubsection{Taxonomy}

The East Indian Sandalwood, belongs to the angiosperm class of 'Magnoliopsida', specifically to the 'Rosids', in the order 'Santalales', family 'Santalaceae', type genus 'Santalum' and species 'S. album'. The common name is East Indian Sandalwood or White Sandalwood as well as Chandan in Hindi.

Tree, semi- parasitic in roots (host plants usually are Cassia, Dalbergia, Azadirachta, Pongamia, Casuarina, Pterocarpus, Acacia etc.). Leaves opposite, simple, decussate, shape varies among six morphological types- ovate, lanceolate, elliptic, linear, big and small. Inflorescence axillary or terminal cymose panicles. Flowers: small, purplish brown, unscented. Fruits: drupe, purplish when fully matured, single seeded, shape- round to oblong. Seed: polymorphic, lacking testa, dicotyledonous embryo, endosperm fleshy. Basic chromosome number of the genus is $\mathrm{x}=10$, few are polyploids. Twenty different species, a few are commercially important; include $S$. lanceolatum, $S$. yaasi, $S$. spicatum, $S$. austrocaledonicum. In India, more than $90 \%$ of sandalwood forest lies in Karnataka and Tamil Nadu covering an area of 8,300 sq. km. Andhra Pradesh, Kerala, Maharashtra, Madhya Pradesh and Orissa are some other states where sandalwood trees are found (Figure 1.1). A total area of about 9, 600 sq. km. harbors sandalwood plantation (Rao and Bapat, 1992). Santalum album L. is distributed throughout Indonesia in the West, Portuguese island of Timor and on Celebes, Ceylon to Juan Fernandez Islands in the East and from Hawaiian Archipelago in the North to New Zealand in

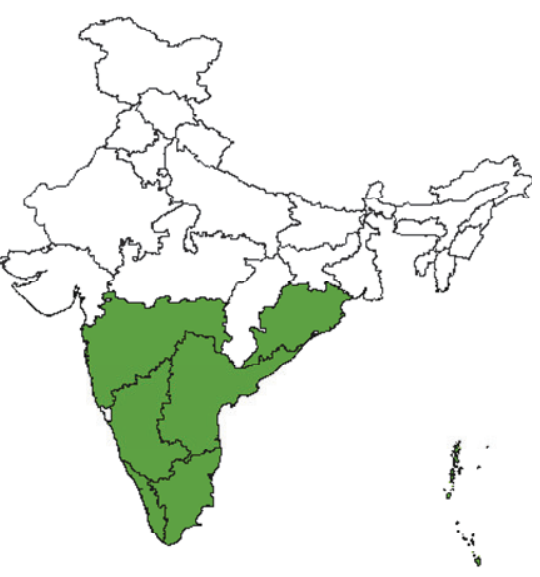
the South.

Figure 1.1 Distribution of East Indian sandalwood in Indian subcontinent (modified from Srinivasan et al., 1992) 


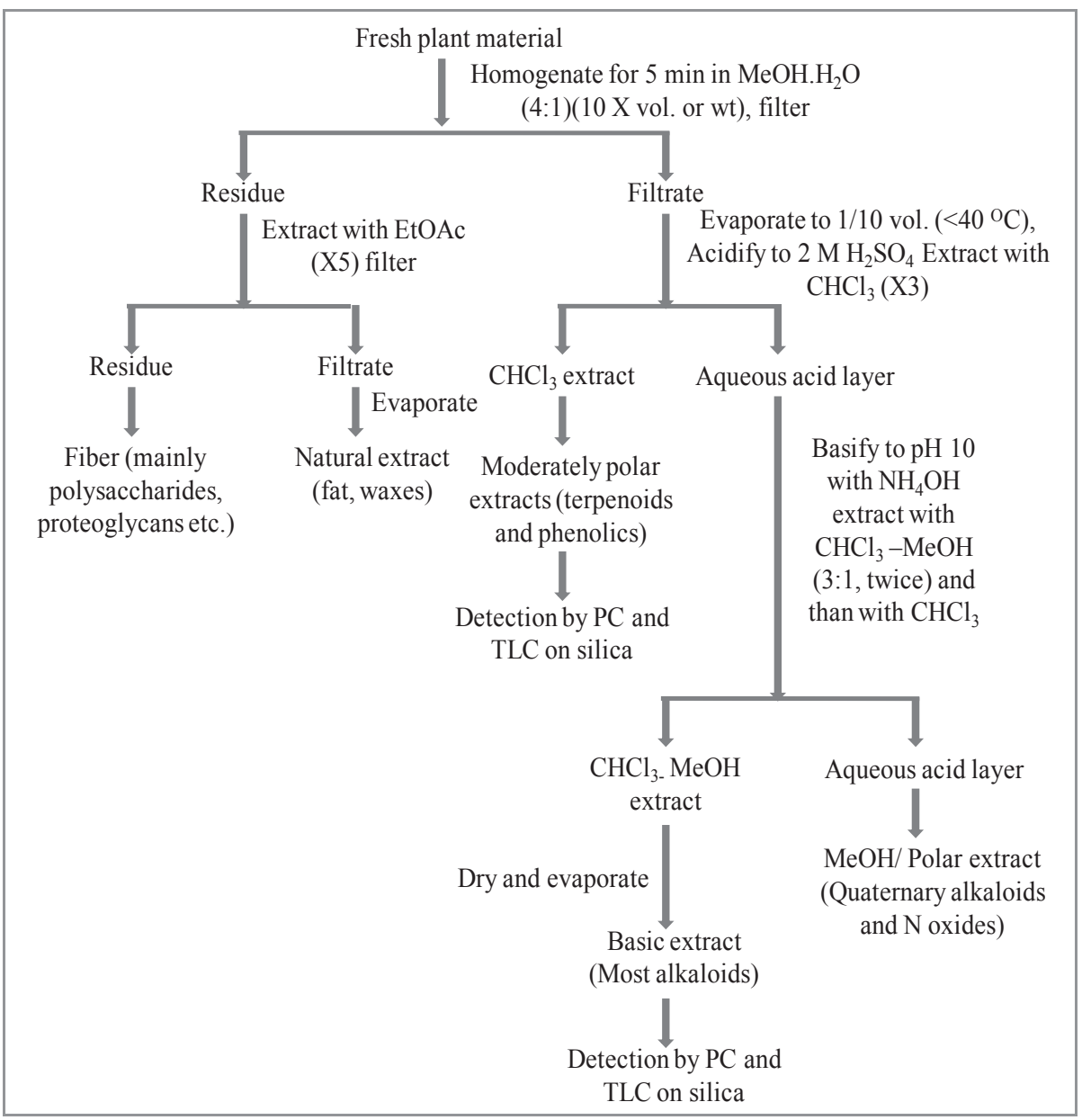

Appendix F.3 Flowchart showing the Harborne protocol (Harborne, 1998). 

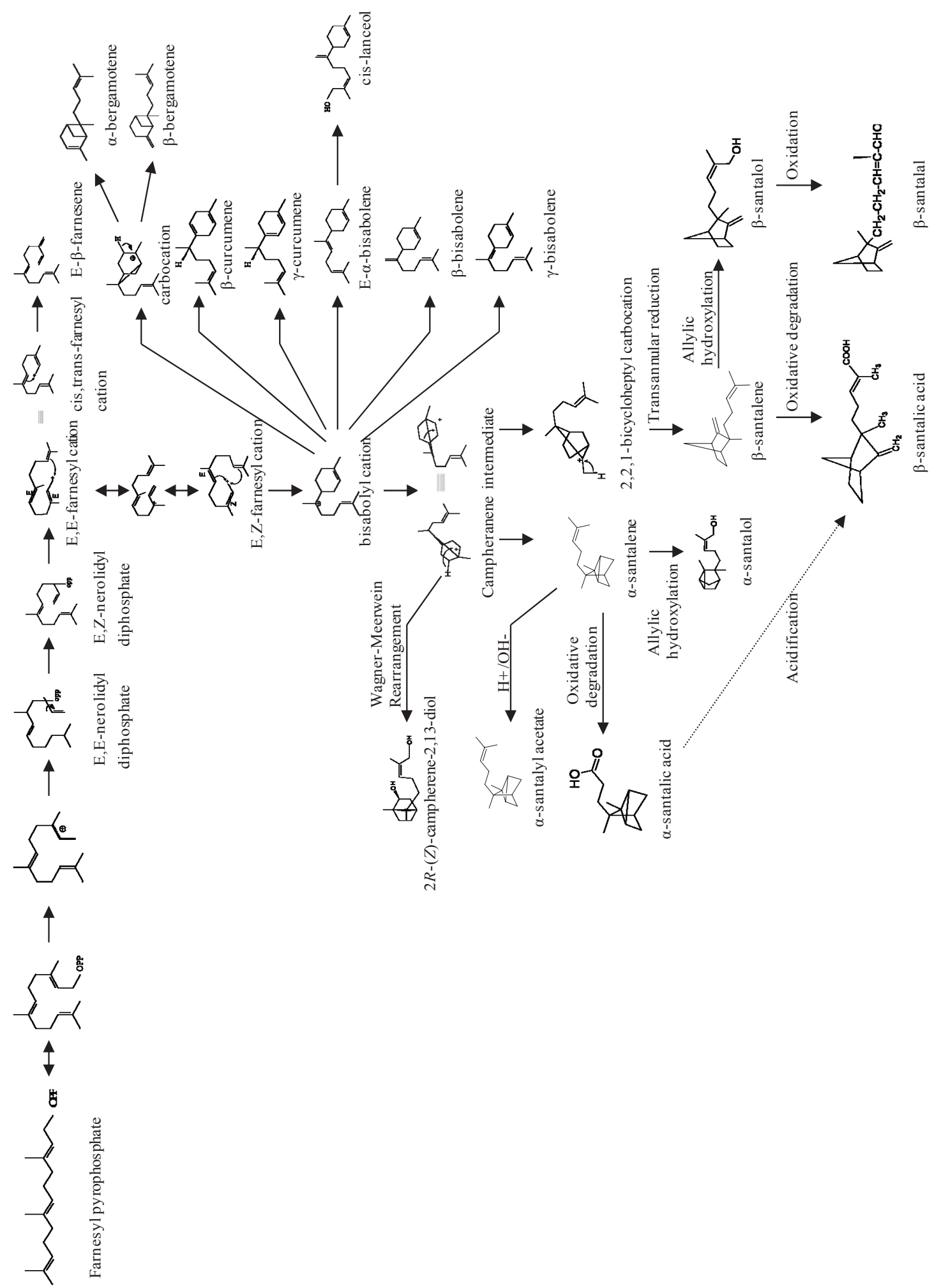

Appendix F.4 Proposed sandalwood sesquiterpenoid biosynthetic pathway schemes (modified from Sell, 2003). 


\section{CURRICULUM VITAE OF AUTHOR}

Biswapriya Biswavas Misra was born on the $4^{\text {th }}$ of April, 1982 in the ancient historical capital-city of Orissa state, Cuttack. He received his Bachelor's Honors degree in Botany from Sambalpur University in 2002 and Master's degree in Botany with specialization in Biotechnology and Plant Genetic Manipulation from Utkal University, Orissa, India in 2004. He topped in both the degrees and received University Gold Medals. He was a recipient of Junior and Senior Research Fellowships from Council of Scientific \& Industrial Research, India and qualified in GATE. He pursued his doctoral studies in the field of Plant Biotechnology on the thesis entitled, "Prospecting of phenylpropanoids and terpenoids in East Indian Sandalwood (Santalum album L.)" under the supervision of Professor Satyahari Dey at the Department of Biotechnology, Indian Institute of Technology, Kharagpur, India. While continuing doctoral studies he got trained in plant tissue and organ culture, animal cell culture, spectroscopy and chromatography methods, metabolite profiling, microscopy and histochemistry, molecular biology, immunology, bioassays, bioinformatics as well as statistical analysis and computer skills. The sequences obtained from the cloning studies have been submitted with the NCBI GenBank Public Database. From the doctoral work, three Indian patents have been filed and four manuscripts are being communicated to peer reviewed journals. During this period, he got an opportunity to work at Eidgenössische Technische Hochschule (ETH), Zurich, Switzerland at as an exchange research student through Indo Swiss Bilateral Research Initiative (ISBRI), in a project entitled "Arabidopsis isoprenoid metabolism by means of protoplast transformation, lossof-function mutant, genotyping and phenotyping and confocal based gene co localization studies" under the supervision of Prof. Wilhelm Gruissem and Dr. Eva Vranova, for 5 months starting August, 2009. During the doctoral studies his research activities involved extraction and characterization of sandalwood enzymes and metabolites, testing the biological activities and obtaining clones for several metabolically important biosynthetic pathway genes. His research interests include secondary metabolism, plant metabolic engineering, plant functional genomics, metabolomics, developmental biology and natural products research. More information regarding the author's research interests, and information included in Appendix in this thesis are found at the personal webpage, http://sites.google.com/site/bbmisranow/. 